\section{B A Institute of \\ YK Business Administration \\ 六下 \\ Karachi \\ Leadership and Ideas for Tomorrow}

Business Review

Volume 11 Issue 2 July-December 2016

7-1-2016

\title{
Lead lag relationship and directional asymmetry in stock returns of small and large portfolios: Evidence from the Karachi Stock Exchange
}

\author{
Ajid Ur Rehman \\ Dongbei University of Economics and Finance Dalian, P.R. China \\ Ataullah Shah \\ Institute of Management Sciences, Peshawar, Pakistan
}

Follow this and additional works at: https://ir.iba.edu.pk/businessreview

Part of the Economics Commons

\section{(c) (1)}

This work is licensed under a Creative Commons Attribution 4.0 International License.

\section{Recommended Citation}

Rehman, A. U., \& Shah, A. (2016). Lead lag relationship and directional asymmetry in stock returns of small and large portfolios: Evidence from the Karachi Stock Exchange. Business Review, 11(2), 1-15. Retrieved from https://doi.org/10.54784/1990-6587.1064 


\title{
ARTICLE
}

\section{Lead-Lag Relationship and Directional Asymmetry in Stock Returns of Small and Large Portfolios: Evidence from the Karachi Stock Exchange}

\author{
Ajid Ur Rehman \\ Dongbei University of Finance and Economics Dalian, P.R. China \\ Attaullah Shah \\ Institute of Management Sciences, Peshawar, Pakistan
}

\begin{abstract}
We explore whether systematic lead-lag relationships exist among the returns of small and large portfolios and whether such portfolios show symmetrical responses to good and bad news. Regression analysis conducted on sample small and large portfolios selected from listings at the Karachi Stock Exchange shows that small stocks follow large stocks quickly in bear-market conditions but slowly in bull-market conditions. This implies that positive information is absorbed more slowly in the prices of smaller stocks than in that of larger stocks.
\end{abstract}

Key Words: Lead-Lag Relationship, Directional Asymmetry, Smallest and Largest Stocks, Karachi Stock Exchange

\section{Introduction}

Stock market is an important centre of financial activity in a country as it helps in price discovery of financial assets, and provides liquidity to primary markets, and serves as a good economic indicator. Karachi Stock Exchange (KSE) is the largest stock market of Pakistan. It is a core window for both domestic and foreign investors to invest their funds. The movement across KSE-100 Index is mainly driven by large capitalization stocks like Oil and Gas Development Corporation, Pakistan Tobacco Company, National Bank of Pakistan, Karachi Electric Supply Company. At the same time KSE 100-Index has also some small market capitalization companies like Quice Foods Limited, Adam Sugar Mills, Yusuf Weaving Mills, Lakson Tobacco. These small stocks move in integration with large capitalization stocks. However, evidence suggests that large stocks usually lead the small stocks (Lo and MacKinlay, 1990; Cen et al. 2013). This study is based on lead lag relationship of small and large stocks returns. If there is a systematic lead lag relationship between returns of small and large stocks it will be easy for a portfolio manager to devise a strategy to estimate movements in one group of stocks with the help of the other. In this way s/he can follow a strategy of buying winners and selling losers to earn above normal profit. However, contrary to lead-lag patterns the Random Walk Hypothesis introduced by Bachelier's (1900) in his thesis "Theory of Speculation". It postulates that prices of stocks evolve randomly and thus stocks prices can't be predicted. It is consistent with efficient market hypothesis. This area has attracted enormous research. Random walk hypothesis has been supported in a number of early studies (Cootner, 1964; Fama, 1965, 1970). Stock prices unpredictability is the essential feature of random walk hypothesis. However, recent studies have evidence in support of stock returns predictability which has surprised the 
advocates of efficient market hypothesis. Because of this reason importance of this area has increased considerably from the point of view of financial economists.

Different studies have been conducted to explain the existence of lead-lag relationship between stock returns. In this regard the discussion goes back to Fisher (1966) who reported that non-synchronous trading brings autocorrelation between stock returns. In preceding studies lead-lag pattern was studied by sorting portfolios on the basis of different characteristics. Lo and Mackinlay (1990) and Cohen et al. (1986) reported that lead-lag pattern is due to thin trading. Thinner trading occurs as far as trading in small stock is concerned. This is due to the fact that investors wait until they see enough evidence that prices of small stocks are going to adjust to new information. Thus a lag in response of the market is created to adjust the prices of small stocks. This size associated with lead-lag relationship is attributed to the mechanism of dissemination of information by Lo and Mackinlay (1990). Availability of information also plays an important role in lead-lag relationship of stock returns as highlighted by Chan (1993). According to findings of Chan (1993) findings large stocks are more focused by institutional investors compared to small stocks. More information and analysis are produced regarding large stocks. So, the investors who only specialize in small stocks are left only to rely in the price movement of large stocks because movements in their prices, large stocks indicate quality of information generated by institutional investors. Investors follow price movements of large stocks to predict movements in prices of small stocks. Chan (1993) views were objected by Badrinath et al. (1995). They argued that lead-lag relationship is more related to institutional ownership than size itself.

Recent studies have shifted the focus of lead-lag patterns from more fundamental explanations to behavioral explanations. Studies by Hong et al. (2007); Merton (1987) and Hong \& Stein (1999) reported slow diffusion of information among different segments of markets because of limited ability of humans to process all available information. This limited cognitive ability lead to lag of information reaching from one segment to other which in turns create lead and lag phenomena in asset returns.

One important empirical study in this regard is the study of Hong et al. (2007). Their main hypothesis was that the propensity of an industry to lead movement of the stock market index is linked with its ability to predict various economic indicators. They found evidence in support of their hypothesis, even after controlling for well-known stock market predictors."

Another important aspect is the directional asymmetry in returns behavior of small and large stock returns. Directional asymmetry is when two things going in different directions. McQueen, et al. (1996) proved that directional asymmetry exist in returns of small and large stock portfolios. Their study also reported that some small stocks have a tendency to respond slowly to good macroeconomic news. This provides another opportunity to find out stocks with rapid response to good macroeconomic news.

The objectives of the study are: to (i) find whether returns of small stocks or large stocks lead the market returns; (ii) to investigate lead and lag relationship between the returns of small and large stocks; (iii) to find directional asymmetry in returns of small and large stocks; and (iv) to investigate the direction and degree of responsiveness of small stock returns in up and down market conditions. This paper has idiosyncrasy in a way that no previous research study in Pakistan has investigated directional asymmetry in up and down market conditions.

This remainder of this study is organized as follows: in section 2, existing literature on lead and lagged pattern is discussed in details in Section 3, the sample framework, sources 
of data, measurement of explained and explanatory variables and statistical models are discussed in Section 4, findings are discussed and analyzed, section 5, concludes the study.

\section{Literature Review}

The lead lag relationship of stock returns has been analyzed and studied by different researchers at different point of time using different methodologies. An important methodology used in different studies is the cross autocorrelation in portfolio returns. McQueen, et al. (1996) found that small stocks returns can be predicted from the movements in returns of large stocks. When the returns on large stocks are negative, then small stocks have high concurrent beta while their lagged beta is highly insignificant. On the other hand, if large stocks have positive trend small stocks have small beta and significant lagged beta.

MacQueen et al. (1996) based their findings on Leo and Mackinlay (1990) cross autocorrelation puzzle. According to this puzzle small stocks reflect a delayed response to positive news and a quick response to common negative news. They further analyzed the source of contrarian profits. Contrarian refers to investor who makes his investment decisions contrary to current market sentiments. For example, if market is currently at rage for energy stocks and pharmaceutical stocks are out of touch. A contrarian will opt for pharmaceutical stocks because he is thinking that these stocks are currently underpriced and will be profitable in future. Thus a contrarian buys today's looser. While analyzing the source of contrarian profits they argued that there is a correlation between the returns on a portfolio of small stocks with the lagged returns on a portfolio of large stocks.

Another important aspect was the size asymmetry. Leo and Mackanly (1990a) also argue that there is size asymmetry, i.e. the returns of large stocks are not correlated with the lagged returns of small stocks. Boudoukh et al. (1994) on the contrary however argue that this cross autocorrelation between the size sorted portfolios can also be attributed to autocorrelation of small stocks portfolios. However, Leo and Macainlay (1990a, 1991b) argue that such autocorrelation of small stocks portfolios cannot appeal to the traditional no synchronous trading criticisms. They found that the systematic lead - lagged patterns among returns of large and small stocks is an important source of the contrarian profits. With these findings a search for new, viable and suitable begun to explain why small stock returns can be predicted by returns of the large stocks.

Different researchers have views about this asymmetric pattern. Conrad, et al. (1997) reported size asymmetry in conditional variances. They argue that behavior and mean of small stock returns is led by the volatility patterns of large market stocks. Chan (1993) explained the asymmetric patterns of cross autocorrelation of returns of large stocks with the returns of small stocks. He argued that this cross autocorrelation might arise because investors are more informed about large stocks, having lower marginal costs of information. (e.g., Ho \& Michaely 1988). Chan (1993) views cost to acquire information depends on investor risk preferences when the information is not incorporated in the price. This shows that at equilibrium marginal cost for acquiring information is the same for all stocks, but despite this cost of acquiring information may differ. From this it is clear that all public information may not be incorporated in prices of small stocks. With a striking finding that market makers add noisy signals to their stocks. They set the prices of their assets according to their future expected values owing to their signals. However, there is a heterogeneity in signals which creates information asymmetry patterns that play their roles in cross autocorrelation. There exist stocks of less noisy signal. The price changes for these stocks are more strongly correlated with changes in future prices of noisier stocks. This shows that prices of less noisy stocks slowly incorporate the available information. 
Boudoukh et al. (1994) categorize the existence explanation for this correlation into three school of thoughts: "Loyalists," "Revisionists," and "Heretics". Loyalists argue information is processed rationally by the market. They believe that strong autocorrelation at shorter periods are not due to the fundamentals but instead they can be attributed to correlation that arises due to market frictions. The magnitude and pattern of this autocorrelation may be due to measurement of error in data which may be due to nonsynchronous trading patterns; difference is prices or bid as spreads (Conrad, Gultekin, and Kaul, 1997). Institutional structures involving different market mechanisms and structures and trading periods also account for this autocorrelation pattern. Microstructures such as handling and processing of market information, holding and inventory holding mechanisms can also lead to these autocorrelation patterns.

Advocates of the second school of thought "the revisionist" argue that markets are efficient but however even in the frictionless markets this autocorrelation of short horizon stock returns can be found. Their view is that these autocorrelation patterns are driven by time varying risk premiums. Changing risk premiums, they argue, can be explained by inter temporal asset pricing models, such as conditional versions of the arbitrage pricing theory or the consumption-based asset pricing model. That is, variation in risk factors, such as past market returns, past size returns, or interest rate spreads, can induce variation in short-horizon risk premiums (Conrad, Gultekin, and Kaul, 1991).

Heretics argue that markets are not rational however profitable trading strategies do exist. They further argue that in pricing of securities psychological factors are very much important. They attribute the market predictability to stock market bubbles and over reaction.

Each of the above schools of thought has some empirical support however all of the empirical characteristics of data do not support any of them. For example, Mech (1993) found some empirical support for Loyalists. Transaction cost arguments of Loyalists was consistent with Mech's findings. He empirically found that 'cross sectional stocks with higher bid as spread reflects more predictability than stocks with lower bid ask risk. However, Mech time series findings were unable to support his explanation.

McQueen et. al. (1996) extends prior work into two directions. First they offer a new challenge to those who seek the explanations of cross autocorrelation pattern between large stock and small stock returns by documenting a new empirical attribute of the data, i.e.' the directional asymmetry. They showed that in up and down market this cross autocorrelation is asymmetric. In months when short market fall they found high concurrent beta for small stocks and significantly lagged betas. In months when stock market rises they found small concurrent beta for small stock and highly significant positive lagged beta. Thus, on both current and lagged markets proxy returns beta exhibit a directional asymmetry. They further found that both large and small stocks respond quickly to negative macroeconomic views, however some small stocks respond with a delay to noneconomic news. Their findings were consistent with different data patterns i.e. weekly and monthly returns. Their findings were inconsistent with Loyalists and Revisionist school of thoughts those supporting a symmetric response to macroeconomic news.

Further evidence on Heretics school can be found in empirical work of Sias and Starks (1994). They argued that this delay in response is caused by the herding behavior of institutional investors. It was confirmed by the work of McQueen et al. (1996) who empirically found that when the macroeconomic news is good long delays in small stock returns are caused by institutional herding behavior. 
Many researchers had given evidence regarding directional asymmetry. Odierand Solnik (1993) and Bae and Karolyi (1994) report a directional asymmetric pattern for good and bad news in volatility spillovers for stock returns across international markets. Work of Domian, et al. (1995) shows that relation between stock returns and inflation is somewhat asymmetric. They report a positive quick response to unexpected decrease in inflation and negative response to unexpected decrease in inflation.

McQueen and Thorley (1993) reported an empirical finding that measured directional asymmetries in the analysis of U.S economy. They found that asymmetry in sticky prices can be used to explain stagflation. All these evidences from empirical researches suggests that relationship in good macroeconomic conditions is quite different than bad macroeconomic conditions and thus make good market conditions more interesting to study.

Recent studies have shifted the focus of directional asymmetry from more fundamental explanations to behavioral explanations. Studies by Hong et al., 2007; Merton 1987; Hong and Stein 1999) reported slow diffusion of information among different segments of markets because of limited ability of humans to process all available information. This limited cognitive ability lead to lag of information reaching from one segment to other which in turns create lead and lag phenomena in asset returns.

Another important empirical study in this regard is the study of Hong et al. (2007). Their main hypothesis was that the propensity of an industry to lead movement of the stock market index is linked with its ability to predict various economic indicators. They found evidence in support of their hypothesis, even after controlling for well-known stock market predictors.

\section{Hypotheses}

Based on the above discussion following hypothesis are developed.

\section{Which Stocks Lead the Market?}

$H_{0}$ : Market returns are not led by the largest stock portfolios.

$H_{1}$ : Market returns are led by the largest stock portfolios.

\section{Directional Asymmetry}

$H_{0}$ : When market is in moving up or down there is no directional asymmetry in the current and lagged returns of the smallest and the largest stock portfolio.

$H_{1}$ : When market is moving up or down there is directional asymmetry in the current and lagged returns of the smallest and the largest stock portfolio

\section{Methodology}

This section discusses the sample framework, sources of data, measurement of explained and explanatory variables, and statistical models.

\section{Sample and Data Sources}

This study analyzes an extensive set of data. The analysis includes 5 years of weekly data of 200 firms selected from all the sectors of KSE over a period of January 2004 to April 2008.These 200 firms were selected on the basis of high turnover. And the reason why we 
stopped at April 2008 is that the Karachi Stock Exchange was declared frozen after steep downfall from April 2008 onwards. The following period did not show normal behavior of the Karachi Stock Exchange and hence inclusion of this period could pose a serious problem for generalization of the results. For market returns weekly data of the KSE-100 Index was taken. Data were collected from: www.bercorder.com and official website of the Karachi Stock Exchange i.e. www.kse.com.pk.

\section{Portfolio Development}

As far as the sorting of large and small cap firms is concerned, this research study follows the work of Rehman and Rehman (2010). They took an average value of market capitalization for sorting of their portfolios. Further dividing the portfolios into five portfolios is based on the work of Chou et al (2006).

\section{Weekly Data Sorting}

Portfolios are sorted on the basis of their market capitalization. In case of analysis of weekly data companies are sorted on the basis of their respective weekly market capitalization. Companies are then sorted in 5 portfolios i.e. P1, P2, P3, P4, P5. This assignments is done in ascending order where P1 refers to portfolio consisting of the smallest firms based on their market capitalization, while P5 consists of the largest firms. There were 233 weeks and each week included 5 portfolios.

\section{Main Variables of the Study}

\section{Market Capitalization}

Market capitalization refers to shares issued multiplied into their market values. Market capitalization is used to categorize the stocks into small and large stocks portfolios.

\section{Stock Returns}

Stock returns are calculated from the prices of stocks using the following formula:

$$
R_{t}=\operatorname{Ln}\left(P_{t} / P_{t-1}\right)
$$

where $R_{t}$ is the return of each portfolio at time $\mathrm{t}, \mathrm{Ln}$ is the natural $\log , P_{t}$ is the closing price at end of a particular week and $P_{t-1}$ is the opening price at the start of a particular week.

\section{Index Returns or Market Returns}

Market returns are calculated from the changes in KSE 100 Index. The formula for calculating the market returns is given as follow:

$$
R_{m}=\operatorname{Ln}\left(I_{t} / I_{t-1}\right)
$$

where $R_{m}$ is the market or index returns at time t, Ln is the natural $\log , I_{t}$ is index closing value at the end of each week time $\mathrm{t}$, and $I_{t-1}$ is the index opening value at the start of the week.

The dependent variable is Index or market returns. The independent variables are on the left side. Through this model it is to be investigated which portfolio of stocks leads the

6 
market? The portfolio of stock that leads the market is then used as a proxy to find out how portfolio of the smallest stocks responds to returns of portfolio that leads the market.

\section{Statistical Model}

In this study two types of regression models are used to investigate the relationship between returns of small stocks portfolios and returns of large stock portfolios. McQueen et al. (1996) used ARCH regression to report for directional asymmetry. This study also uses OLS regression to analyze the directional asymmetry.

\section{Ordinary Least Square Method}

The first regression model is the simple Ordinary Least Square Method to investigate whether the market is led by returns of large stocks or returns of small stocks' portfolio. Following are the model specifications for the largest stocks' portfolio.

$$
r_{m, t}=\alpha+\beta_{0} r_{5, t}+\beta_{1} r_{5, t-1}
$$

where

$r_{m}$ is the market index returns,

$\alpha$ is the regression constant,

$\beta_{0}$ is coefficient of returns of the largest portfolio,

$r_{5, t}$ is the returns of the largest portfolio at time $\mathrm{t}$

$\beta_{1}$ is the coefficient of lagged returns of the largest stocks at time $\mathrm{t}-1$

$r_{5, t-1}$ is the lagged returns of largest stocks' portfolio at time t-1

Similar OLS method is used for returns of small stocks' portfolio. The model specifications are given below.

$$
r_{m, t}=\alpha+\beta_{0} r_{1, t}+\beta_{1} r_{1, t-1}
$$

All the parameters remain the same except the returns of small stocks' portfolio denoted by $r_{1}$

\section{Symmetric and Asymmetric ARCH Regression Model}

The ARCH (Autoregressive Conditional Heteroskedesticity) model is used to regress the returns of the smallest portfolios on current and lagged returns of largest portfolios. The model specifications are.

$$
\begin{aligned}
& r_{1, t}=\alpha+\beta_{0} r_{5, t}+\beta_{1} r_{5, t-1}+\mu_{t} \\
& \mu_{t} \approx N\left(0, h_{t}\right), h_{t}=\gamma_{0}+\gamma_{1} \mu_{t-1}^{2}
\end{aligned}
$$

Returns of the smallest stocks portfolio $r_{1, t}$ are regressed on current $r_{5, t}$ and lagged returns $r_{5, t-1}$ of largest stocks allowing autoregressive conditional heteroskadecticty. 
Business Review - Volume 11 Number 2

\section{Findings and Analysis}

Table 1 reports summary statistics. These statistics are for weekly returns of portfolio P1, P2, P3, P4, and P5. $\rho_{1}, \rho_{2}$ and $\rho_{3}$ represents autocorrelation of these five portfolios up to three lags. $\rho_{1}^{U P}$ and $\rho_{1}^{D N}$ are autocorrelations in up and down market respectively. $S(\rho)$ is the standard error for autocorrelations. In up and down market autocorrelation is reported by taking $r_{5}>0$ and $r_{5}<0$ respectively. Where $r_{5}$ are returns of the largest portfolio?

Table 1: Descriptive Statistics

\begin{tabular}{cccccc}
\hline \hline Statistic & $\mathrm{P} 1$ & $\mathrm{P} 2$ & $\mathrm{P} 3$ & $\mathrm{P} 4$ & $\mathrm{P} 5$ \\
\hline $\begin{array}{c}\text { Mean } \\
\begin{array}{c}\text { St. } \\
\text { Deviation }\end{array}\end{array}$ & 0.0005 & 0.0013 & 0.0015 & 0.0009 & 0.0013 \\
$\rho_{1}$ & 0.0729 & 0.0822 & 0.0723 & 0.0805 & -0.0759 \\
$\rho_{2}$ & 0.0798 & 0.0985 & 0.0953 & 0.0816 & -0.0290 \\
$\rho_{3}$ & 0.0068 & 0.1543 & 0.0796 & 0.0482 & 0.1104 \\
$S(\rho)$ & 0.056 & 0.053 & 0.058 & 0.054 & 0.052 \\
$p v a l u e$ & 0.001 & 0.0014 & 0.0021 & 0.163 & 0.497 \\
$\rho_{1}^{U P}$ & 0.1989 & -0.1352 & -0.2435 & -0.2147 & -0.3442 \\
$\rho_{1}^{D N}$ & 0.0153 & 0.1642 & 0.1037 & 0.1671 & 0.0129 \\
\hline \hline
\end{tabular}

\section{Which Stocks Lead the Market?}

In this section, we present and discuss results of the OLS and ARCH models to investigate the lead-lag pattern in portfolio returns as well as the directional asymmetry in up and down markets.

Table 2 shows that $\mathrm{R}$ square value is 0.6885 which is quite high and depicts that independent variable have greater explanatory power. It means $68.85 \%$ changes in the dependent variable market returns are due to independent variables. The coefficient of $\mathrm{p} 5$ and the lag value of $\mathrm{p} 5$ are statistically significant at $99 \%$ significant level with a $t$ value of 22.53 and 3.41 respectively. Thus it implies that market returns are led by both current and lagged returns of the largest stocks. The F value is 0.000 which is less than 0.05 which shows that overall model is statistically significant. 
Table 2: Regression of Market Returns (rm) on the Largest Portfolio (P5)

$$
r_{m, t}=\alpha+\beta_{0} r_{5, t}+\beta_{1} r_{5, t-1}
$$

\begin{tabular}{|c|c|c|c|c|}
\hline \multicolumn{5}{|l|}{$\begin{array}{l}\text { Indicators of Overall Model } \\
\text { Significance }\end{array}$} \\
\hline Dependent Variable & \multicolumn{2}{|l|}{$\mathrm{rm}$} & & \\
\hline \multicolumn{5}{|l|}{$\begin{array}{l}\text { Coefficient of determination } \\
\text { Square }\end{array}$} \\
\hline $\mathrm{R}$ square adjusted & \multicolumn{2}{|l|}{0.6885} & & \\
\hline $\mathrm{F}(2,228) \mathrm{P}=0.000$ & \multicolumn{2}{|l|}{255.15} & & \\
\hline \multicolumn{5}{|l|}{$\begin{array}{l}\text { Significance of Independent } \\
\text { Variables }\end{array}$} \\
\hline Independent variables & Coef. & Std. Err & $\mathbf{t}$ & $\mathbf{P}>|\mathbf{t}|$ \\
\hline $\mathrm{p} 5$ & .8023915 & .0356221 & 22.53 & 0.000 \\
\hline L1 & .1214809 & .0356072 & 3.41 & 0.001 \\
\hline
\end{tabular}

\section{Current Returns of the Largest Stock}

Table 2 shows that current returns of the largest stock portfolio have greater explanatory power of market returns. The coefficient of 0.80 is a very healthy one. It shows if market returns changes by 1 unit, 0.80 changes is due to current returns of the largest stock portfolio. The $\mathrm{p}$-value for the current returns is 0.000 , which is less than standard value of 0.05. These results show that independent variable P5 (current returns of the largest stock portfolio) is statistically significant.

\section{Lagged returns of the Largest Stock Portfolio}

Table 2 shows that coefficient for a lagged return of the largest stock portfolio is 0.12 .It shows if market returns changes by $1,0.12$ change is due to lagged returns of the largest stock portfolio. Though it is very small contribution; however, it has statistical significance with a $\mathrm{p}$ value of 0.001 .

Model specification for the smallest stocks portfolio is:

$$
r_{m, t}=\alpha+\beta_{0} r_{1, t}+\beta_{1} r_{1, t-1}
$$

Table 3 shows an $\mathrm{R}$ value of 0.2680 which is very small as compared to the $\mathrm{R}$ value for returns of the largest stocks 0.688 . This shows current and lagged returns of the smallest stock portfolio have a weak explanatory power of market returns. The over model is statistically significant with a $F$ value of 0.0000 much less than 0.05 slandered value. Furthermore, the individual coefficient of $\mathrm{p} 1(0.522)$ is significant at $99 \%$ significance level with a $t$ value of 9.28 . 
Table 3: Regression of Market Returns (rm) on the Smallest Portfolio (P1).

\begin{tabular}{|c|c|c|c|c|c|}
\hline $\begin{array}{l}\text { Indicators of Overall } \\
\text { Model Significance }\end{array}$ & & & & & \\
\hline Dependent Variable & $\mathrm{rm}$ & & & & \\
\hline R square adjusted & 0.2680 & & & & \\
\hline $\mathrm{F}(2,228), \mathrm{P}=0.000$ & 43.10 & & & & \\
\hline \multirow{2}{*}{\multicolumn{6}{|c|}{$\begin{array}{l}\text { Significance of } \\
\text { Independent Variables } \\
\text { Independent variables }\end{array}$}} \\
\hline & & & & & \\
\hline & Coef. & Std. Err & $\mathbf{t}$ & $\mathbf{P}>|\mathbf{t}|$ & Beta \\
\hline $\mathrm{P} 1$ & .5223356 & .056264 & 9.28 & 0.000 & \\
\hline L1 & -.0294808 & .0561423 & -0.53 & 0.600 & \\
\hline
\end{tabular}

\section{Current Returns of the Smallest Stock Portfolio}

The coefficient for current returns of the smallest stock portfolio is less than the current returns of the largest stock portfolio (see Table 3). This shows the weak role played by current returns of the smallest stocks in leading the market. The lagged return have even negative coefficient and also very small as compared to coefficient of lagged returns of the largest stocks (see table). It is statistically insignificant with a p value of 0.600 greater than 0.05 .

By comparing the results of Table 2 and 3, it is clear that current and lagged returns of the largest stock portfolio better lead the market as compared to current and lagged returns of the smallest stock portfolio. Thus our null hypothesis that returns of the largest stock portfolio do not lead the market is rejected and the alternate hypothesis is accepted.

Moreover, these results indicate that returns of the largest stock portfolios can be used as a proxy of market returns. In the following section returns of the smallest stock portfolios are regressed on returns of the largest stock portfolios through ARCH regression (autoregressive conditional heteroskadascticity) both in up and down market conditions for finding directional asymmetry.

\section{Directional Asymmetry}

This section presents the analysis to find out the directional asymmetry between current and lagged returns of the smallest and the largest stocks portfolio using ARCH Regression Model.

Table 4 shows that there is directional asymmetry in the concurrent and lagged stock returns of the smallest and the largest stock portfolio. In panel B of the table this directional asymmetry is measured by taking returns $r_{5}>0$ for up market conditions and $r_{5}<0$ for down market conditions. This directional asymmetry is manifested by returns behavior in up and down market conditions. In Up market conditions, ${ }_{\beta 1}^{U P}=0.386$, however when the market is 
down $\begin{gathered}D N \\ \beta 1\end{gathered}=0.018$. This shows a directional asymmetry in lagged returns of returns. For concurrent returns when market is up $\begin{gathered}U P \\ \beta_{0}\end{gathered}=0.461$, and when the market is down for concurrent returns $\begin{aligned} & D N \\ & \beta_{0}\end{aligned}=0.873$. Thus the concurrent returns also show a directional asymmetry. Thus Null Hypothesis $\left(\begin{array}{ccc}U P \\ H_{0} & \beta_{0}\end{array}=\begin{array}{l}D N \\ \beta_{0}\end{array}\right)$ which states that there is no directional asymmetry in concurrent and lagged returns of the smallest and the largest stocks is rejected at $p$ value of 0.000 . These findings are consistent with the empirical findings of MacQueen et al. (1996). There is not only a directional asymmetry but also returns of small stocks portfolio are responding slowly than returns on large stock portfolios in up market conditions.

Table 4: ARCH Regression of Small Stock Portfolio Weekly Returns on Current and Lagged Returns of the Largest Stock Portfolio Returns

$$
r_{1, t}=\alpha+\beta_{0} r_{5, t}+\beta_{1} r_{5, t-1}+\mu_{t}
$$

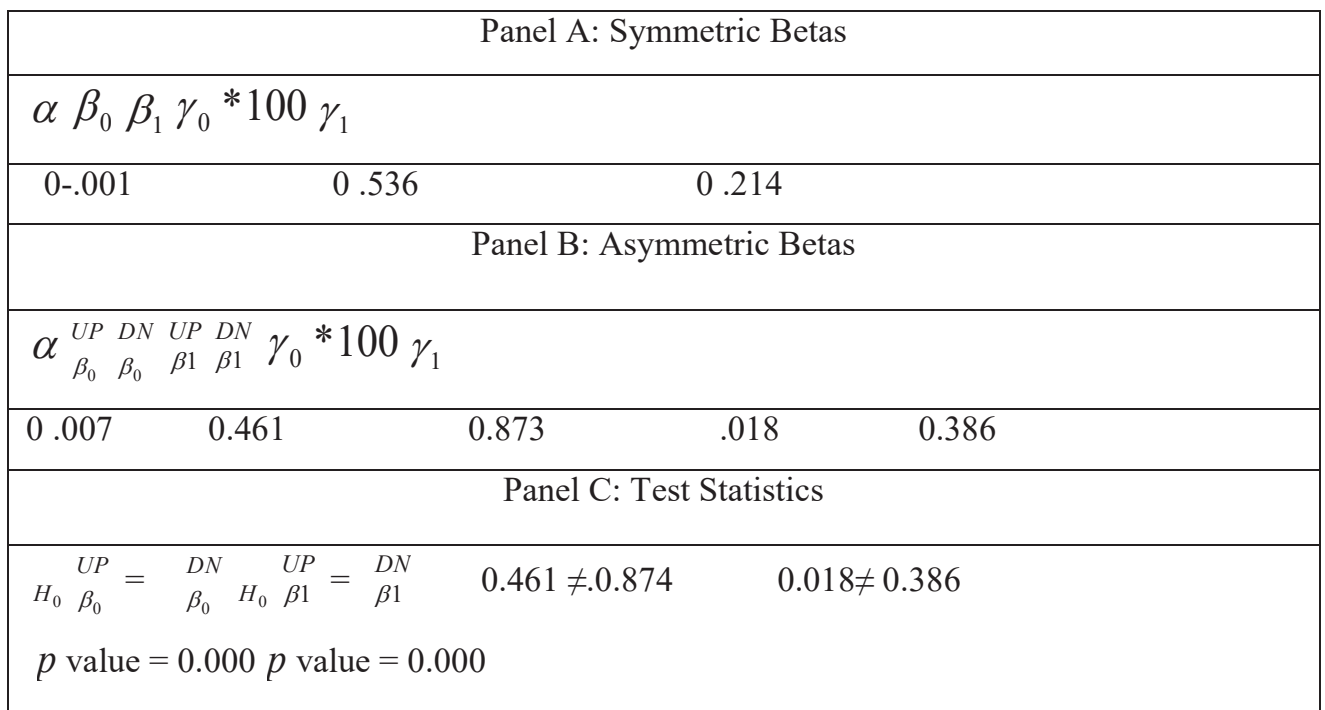

In Table 4, t-statistic are given in parenthesis, $r_{1, t}$ are the returns of small stocks at time $\mathrm{t}, \beta_{0}$ is the coefficient of the largest stock portfolio at time $\mathrm{t}$ and $\beta_{1}$ is the coefficient of the largest stock portfolio at time t-1.The superscripts UP and DN represent the up and down market conditions respectively.

Our prime focus was on lagged beta however the behavior of concurrent returns also needs notice. In up market conditions $\begin{aligned} & U P \\ & \beta_{0}\end{aligned}=0.461$ and ${ }_{\beta_{0}}^{D N}=0.873$. This not only shows a directional asymmetry in concurrent returns but also the low up market beta shows the less exposure of small stocks to good macroeconomic news. Similarly, directional asymmetry is also obvious in lagged returns behavior. The up market beta for lagged returns is 0.386 and down market beta is 0.018 which again shows the directional asymmetry. The lagged beta for up market is very low as compared to lagged beta in down market again showing slowness of 
small stocks to good macroeconomic news. The Null hypothesis $\begin{array}{r}H_{0} \\ \beta 1\end{array}=\begin{aligned} & D N \\ & \beta 1\end{aligned} \quad$ is again rejected at $\mathrm{p}$-value of 0.000 .

Since Karachi Stock Exchange experienced free-fall in mid April 2008, the management decided to freeze the index. In order to verify the above results a robustness test is conducted by removing data beyond April 2008 in the following section.

\section{Robustness Tests by Excluding Data April 2008 Onward}

A robustness test for OLS Regression results is done using less data up to March 2008 because KSE was frozen in April 2008.

Table 5: Regression of Market returns (rm) on the Largest Portfolio (p5)

\begin{tabular}{|l|l|l|l|l|}
\hline \multicolumn{1}{|l|}{$\begin{array}{l}\text { Indicators of Overall Model } \\
\text { Significance }\end{array}$} & \multicolumn{5}{l}{} \\
\hline Dependent Variable & $\mathrm{rm}$ \\
\hline R square adjusted & 0.6497 \\
\hline $\mathrm{F}(2,211), \mathrm{P}=0.000$ & 195.65 \\
\hline $\begin{array}{l}\text { Significance of independent } \\
\text { variables }\end{array}$ & \multicolumn{4}{|l}{} \\
\hline Independent variables & Coef. & Std. Err & t & P $>|\mathbf{t}|$ \\
\hline p5 & .7807715 & .0395711 & 19.73 & 0.000 \\
\hline L1 & .1475694 & .0395583 & 3.41 & 0.000 \\
\hline
\end{tabular}

Table 6: Regression of Market Returns (rm) on the Smallest Portfolio (p1)

\begin{tabular}{|c|c|c|c|c|}
\hline \multicolumn{2}{|l|}{$\begin{array}{l}\text { Indicators of Overall Model } \\
\text { Significance }\end{array}$} & & & \\
\hline Dependent Variable & $\mathrm{rm}$ & & & \\
\hline R square adjusted & 0.2222 & & & \\
\hline $\mathrm{F}(2,211), \mathrm{P}=0.000$ & 30 & & & \\
\hline $\begin{array}{l}\text { Significance of independent } \\
\text { variables }\end{array}$ & & & & \\
\hline Independent variables & Coef. & Std. Err & $\mathbf{t}$ & $\mathbf{P}>|\mathbf{t}|$ \\
\hline P1 & .4482631 & .0577421 & 7.76 & 0.000 \\
\hline L1 & -.0289373 & .0575891 & -0.50 & 0.616 \\
\hline
\end{tabular}

From Table 5 and 6 it is clear that even by removing data after April 2008 due to freezing of the Karachi Stock Exchange, the results do not change. The results for $\mathrm{p} 1$ have statistical significance at 99 percent level with a t value of 7.76. These results again show that market is driven by the largest stock portfolios with statistical significance. 


\section{Robustness Tests of Asymmetric ARCH Regression Using less data}

Model specifications is $r_{1, t}=\alpha+\beta_{0} r_{5, t}+\beta_{1} r_{5, t-1}+\mu_{t}$

Table 7: Robustness Tests of Asymmetric ARCH Regression Using Less Data

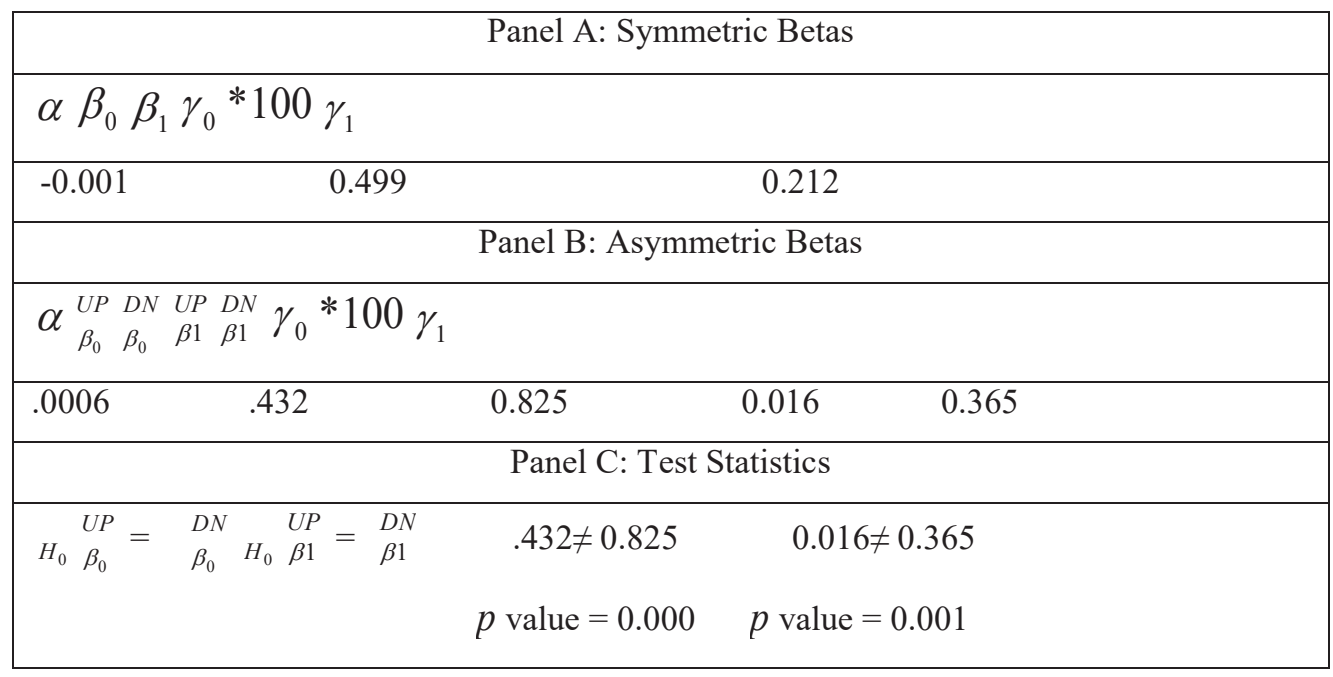

Table 7 shows that the results are robust by excluding April 2008 onward data. Data after April 2008 was removed and then the smallest stock returns were regressed on the smallest stocks returns allowing heteroskedasticity. ARCH regression was conducted both in up as well as down market. Results are consistent with our previous findings. There is not only directional asymmetry in concurrent and lagged returns. The concurrent beta (0.432) in up market is less than concurrent beta in down market conditions. This implies that small stocks respond slowly to positive economic views. Further lagged beta in up market is again lesser than lagged beta in down market. So the results are consistent for both concurrent and lagged returns. Findings have statistical significance with p-values lesser than 0.05 for both current and lagged betas.

\section{Conclusion}

This research study is based on the work of Lo and MacKinlay (1990a, 1990b), Mech (1993), and McQueen, et al. (1996) regarding the ability of large stock portfolios to lead the returns of small stock portfolio. Findings of the study show that portfolios of the largest stock lead the market. Results also show that directional asymmetry exists between returns of large and small stock portfolio. Using ARCH regression, it is found that small stocks indeed respond slowly to good macroeconomic news. Analyses included both concurrent and lagged returns. In both cases directional asymmetry was found in returns of large and small stock portfolio. The findings of this study are consistent with the empirical findings of Grinblatt, etal. (1995) and Keim and Madhavan (1995). One possible explanation for the findings of this study may be that in down market conditions investors tend to sell all stocks quickly. When market is up and news is good, investors buy large easy-to-price stocks and take their time before buying smaller and more volatile stocks. The lead-lag relationship has yet to be formulized into a more plausible trading model that allows for directional asymmetry. We leave this as an open question for future research studies. 
If returns of two groups of stocks possess a systematic lead-lag relationship between them then it will be very easy for a portfolio investor to predict the returns of one group of stock from the return pattern of other group of stocks. In this way the managers can follow a buy-winner and sell-loser strategy and earn above normal profits.

These findings suggest that the capital market of Pakistan appears to be informational inefficient since based on this lead-lag effect forecastibility of assets 'returns is feasible. Our results may be of interest to investors, institutional investors, technical analysts and portfolio managers who are interested in finding profitable portfolio strategies in the Karachi Stock Exchange based on past stock returns. This finding provides portfolio managers and hedge funds with valuation information, to seek new investment opportunities in developed and emerging markets, particularly in the aftermath of the financial crisis of 2007-2009.

\section{References}

Badrinath, S. G., Kale, J. R., \& Noe, T. H. (1995). Of Shepherds, Sheep, and the Crossautocorrelations in Equity Returns. Review of Financial Studies, 8(2), 401-430.

Bae, K.-H., \& Karolyi, G. A. (1994). Good news, bad news and international spillovers of stock return volatility between Japan and the U.S. Pacific-Basin Finance Journal, 2(4), 405 438.

Boudoukh, J., Richardson, M. P., \& Whitelaw, R. F. (1994). A Tale of Three Schools: Insights on Autocorrelations of Short-Horizon Stock Returns. Review of Financial Studies, 7(3), 539-573.

Cen, L., Chan, K., Dasgupta, S., \& Gao, N. (2013). When the tail wags the dog: Industry leaders, limited attention, and spurious cross-industry information diffusion. Management Science, 59(11), 2566-2585.

Chan, K. (1993), Imperfect Information and Cross-Autocorrelation among Stock Prices. The Journal of Finance, 48: 1211-1230.

Chou, P.-H., Li, W.-S., \& Zhou, G. (2006). Portfolio optimization under asset pricing anomalies. Japan and the World Economy, 18(2), 121-142.

Cohen K, Maier S, Schwartz R, Whitcomb D (1986). The microstructure of securities markets, Prentice-Hall, Englewood Cliffs, NJ.

Conrad, J., M. Gultekin, and G. Kaul (1991), 'Asymmetric Predictability of Conditional Variances', Review of Financial Studies, 4, 597-622.

Conrad, J.S., M. Gultekin and G. Kaul, (1997), Profitability of short-term contrarian strategies: implications for market efficiency, Journal of Business and Economic Statistics 15, 397-386.

Domian, D., J. Gilster, and D. Louton, (1995), Expected inflation, interest rates, and stock returns, Faculty of Business Administration, Memorial University of Newfoundland, Working paper.

Donald, K, and A. Madhavan, (1995),Anatomy of the trading process Empirical evidence on the behavior of institutional traders, Journal of Financial Economics, 37, (3), 371-398

Fama E (1965). The behavior of stock-market prices. Journal of Business, 38(1): 34-105

Fama E (1970). Efficient capital markets: A review of theory and empirical work. Journal of Finance, 25(2): 383-417. 
Fisher, L., 1966. Some new stock market indexes, J. Business 39, 191-225.

Grinblatt, M., S. Titman, and R. Wermers, (1995), Momentum investment strategies, portfolio performance, and herding: A study of mutual fund behavior, American Economic Review, 85,1088-1105.

Hong, H., Stein, J., (1999). A unified theory of under reaction, momentum trading and overreaction in asset markets. Journal of Finance. 54, 2143-2184.

Hong, H., Torous, W., Valkanov, R., (2007). Do industries lead the stock market? Journal of Financial Economics. 83, 367-396

Ho, T., and R. Michaely (1988) "Information quality and market Efficiency," Journal of Financial and Quantitative Analysis 23, 53-70

Keim, D., and Madhavan A, (1995), Anatomy of the trading process: Empirical evidence on the behavior of institutional traders, Journal of Financial Economics 37, 371-398.

Lo, A. W., \& A. C. MacKinlay, (1990), "When Are Contrarian Profits Due to Stock Market Overreaction?", Review of Financial Studies, 3, 175-208

Lo, A., \& C. MacKinlay, (1988), Stock market prices do not follow random walks: Evidence from a simple specification test, Review of Financial Studies 1, 897-916.

Lo, A., \& C. MacKinlay, (1990a), When are contrarian profits due to stock market overreaction? Review of Financial Studies 3, 175-205.

Lo, A., \& C. MacKinlay, (1990b), An econometric analysis of nonsynchronous trading, Journal of Econometrics 45, 181-211.

McQueen, G., M. Pinegar, \& S. Thorley, (1996). Delayed reaction to good news and the cross- autocorrelation of portfolio returns, Journal of Finance, 51, 889-919.

McQueen, G., \& S. Thorley, (1993), Asymmetric business cycle turning points, Journal of Monetary Economics 31, 341-362

Mech, T. S., (1993), Portfolio return autocorrelation, Journal of Financial Economics, 34, 307-344.

Merton, R., (1987). A simple model of capital market equilibrium with incomplete information, Journal of Finance. 42, 483-510.

Odier, P., \& Solnik, B. (1993). Lessons for international asset allocation. Financial Analysts Journal, 63-77.

Cootner P,. H. (1964). The random character of stock market prices. MIT Press, Cambridge

Rehman, Ijaz Rehman, K., (2010). Scholar, M. S. (2010). Testing Lead-Lag Relationship Between Small and Large Capitalization Portfolio-Evidence from Karachi Stock Exchange (KSE). World Applied Sciences Journal, 10(5), 590-596.

Ullah, H., \& Shah, A. (2013). Lead-lag relationship in spot and future market: evidence from Pakistani stock market KSE-100 Index, Business Review. 8(1), 135-148

Sias, R., \& L. Starks, (1994), Institutions, individuals, and return autocorrelations, University of Texas Department of Finance, Working paper. 